\title{
Type II NKT cell-mediated anergy induction in type I NKT cells prevents inflammatory liver disease
}

\author{
Ramesh C. Halder, Carlos Aguilera, Igor Maricic, and Vipin Kumar \\ Laboratory of Autoimmunity, Torrey Pines Institute for Molecular Studies, San Diego, California, USA.
}

\begin{abstract}
Because of the paucity of known self lipid-reactive ligands for NKT cells, interactions among distinct NKT cell subsets as well as immune consequences following recognition of self glycolipids have not previously been investigated. Here we examined cellular interactions and subsequent immune regulatory mechanism following recognition of sulfatide, a self-glycolipid ligand for a subset of CD1d-restricted type II NKT cells. Using glycolipid/CD1d tetramers and cytokine responses, we showed that activation of sulfatide-reactive type II NKT cells and plasmacytoid DCs caused IL-12- and MIP-2-dependent recruitment of type I, or invariant, NKT (iNKT) cells into mouse livers. These recruited iNKT cells were anergic and prevented concanavalin A-induced (ConA-induced) hepatitis by specifically blocking effector pathways, including the cytokine burst and neutrophil recruitment that follow ConA injection. Hepatic DCs from $\mathrm{IL}_{-12}{ }^{+/+}$mice, but not $\mathrm{IL}-12^{-/-}$mice, adoptively transferred anergy in recipients; thus, IL-12 secretion by DCs enables them to induce anergy in iNKT cells. Our data reveal what we believe to be a novel mechanism in which interactions among type II NKT cells and hepatic DCs result in regulation of iNKT cell activity that can be exploited for intervention in inflammatory diseases, including autoimmunity and asthma.
\end{abstract}

\section{Introduction}

The liver is strategically situated to receive blood from the intestine that is rich in bacterial and food-derived antigens and is endowed with specialized lymphocytes that both maintain tolerance and generate limited immunity (1). In some ways, the liver is endowed with mechanisms to induce immune tolerance. For example, it has long been known that in the absence of immunosuppression, allogeneic liver grafts can be established, whereas other organ grafts are rejected rapidly (2). In addition, several infections persist in the liver, including the hepatitis B and C viruses and malaria (1). On the other hand, immunity against hepatocytes results in autoimmune liver diseases such as autoimmune hepatitis and primary biliary cirrhosis $(3,4)$, chronic inflammatory diseases that are characterized by loss of tolerance to hepatocytes and biliary epithelium, respectively, and lead to parenchymal cell destruction.

Concanavalin A-induced (ConA-induced) hepatitis in mice is a well-characterized model of $\mathrm{T}$ cell-mediated liver disease and has been extensively used as a prototype mimicking many aspects of human T cell-mediated liver disease (5). It is associated with elevated serum liver enzymes, and hepatic lesions are characterized by a massive granulocyte and $\mathrm{T}$ cell infiltration (predominantly $\mathrm{CD}^{+}$), followed by hepatocyte necrosis and apoptosis. Recently invariant NKT (iNKT; also referred to as hepatic type I NKT) cells have been shown to play a key role in the development of ConAinduced hepatitis: both $\mathrm{J}_{\alpha} 18^{-/-}$and $\mathrm{CD} 1 \mathrm{~d}^{-/-}$mice that lack iNKT cells are resistant to ConA-induced hepatic injury (6-8). NKT cells

Nonstandard abbreviations used: ALT, alanine aminotransferase; AST, aspartate aminotransferase; ConA, concanavalin A; ELISPOT, enzyme-linked immunosorbent spot; iNKT, invariant NKT; mDC, myeloid DC; MFI, mean fluorescence intensity; MNC, mononuclear cell; pDC, plasmacytoid DC.

Conflict of interest: The authors have declared that no conflict of interest exists. Citation for this article: J. Clin. Invest. 117:2302-2312 (2007). doi:10.1172/JCI31602. generally express both the NK1.1 receptor and the TCR and possess characteristics typical of innate immune cells $(9,10)$. NKT cells recognize lipids, glycolipids, and lipopeptides presented by the class I MHC-like protein CD1 (11). The CD1 family consists of 5 distinct isoforms and is divided into 2 groups: humans express group I molecules CD1a, CD1b, CD1c, and CD1e, and both humans and mice express the group II molecule CD1d (11).

CD1d-restricted NKT cells can be broadly categorized into 2 groups. In mice, iNKT cells express a conserved invariant $\alpha \beta T C R$ encoded by the $V_{\alpha} 14\left(V_{\alpha} 24\right.$ in humans) and $J_{\alpha} 18$ gene segments paired with a set of $\mathrm{V}_{\beta}$ chains, mainly $\mathrm{V}_{\beta} 8.2, \mathrm{~V}_{\beta} 7$, or $\mathrm{V}_{\beta} 2(9,10)$. Both the self-glycolipid isoglobotrihexosylceramide and bacterialderived lipids can be recognized by these cells (12-15). Stimulation of iNKT cells with a high-affinity glycolipid ligand ( $\alpha$-GalCer, derived from a marine sponge) results in cytokine secretion, TCR downregulation, and apoptosis (12, 16-19). Type II NKT (i.e., noniNKT) cells use variable TCRs, are distinct from the type $\mathrm{I} \mathrm{V}_{\alpha} 14^{+}$ iNKT cells, and have been identified in both humans and mice (20-23). Although iNKT cells have been shown to be involved in autoimmune diseases, infectious diseases, and asthma as well as in the antitumor immune responses in both experimental models as well as in humans (reviewed in ref. 24), not much is known about type II NKT cells. Recent studies have suggested potential roles of type II NKT cells in the transgenic model of hepatitis B virus infection (25), immune surveillance against tumors (26), Trypanosoma cruzi infection (27), and EAE $(23,28)$. Also, a role for type II NKT cells in the pathogenesis of ulcerative colitis has been suggested (29). However, to our knowledge, cellular interactions among NKT cell subsets and their potential role in the regulation of an iNKT cell-mediated disease have not previously been investigated.

Sulfatide, 3 '-sulfated galactosyl ceramide derived from myelin, binds promiscuously to several human CD1 molecules (30) and to murine CD1d and is recognized by type II NKT cells $(23,28)$. 
A

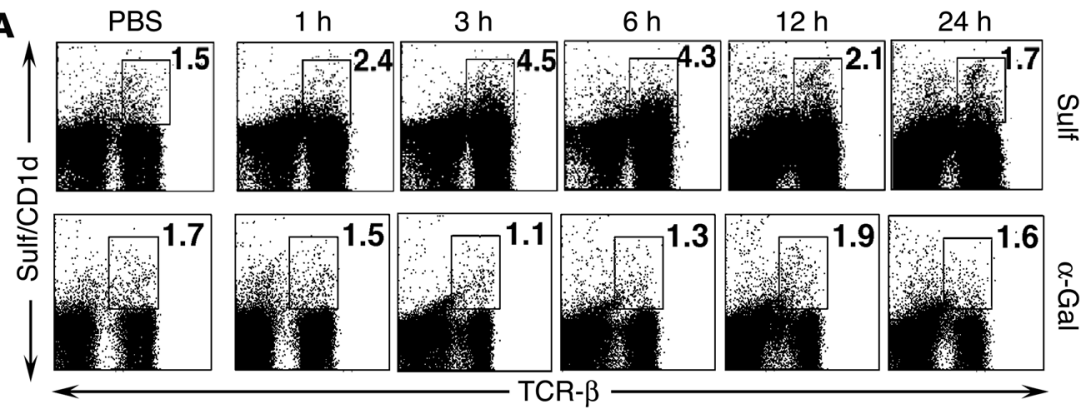

B

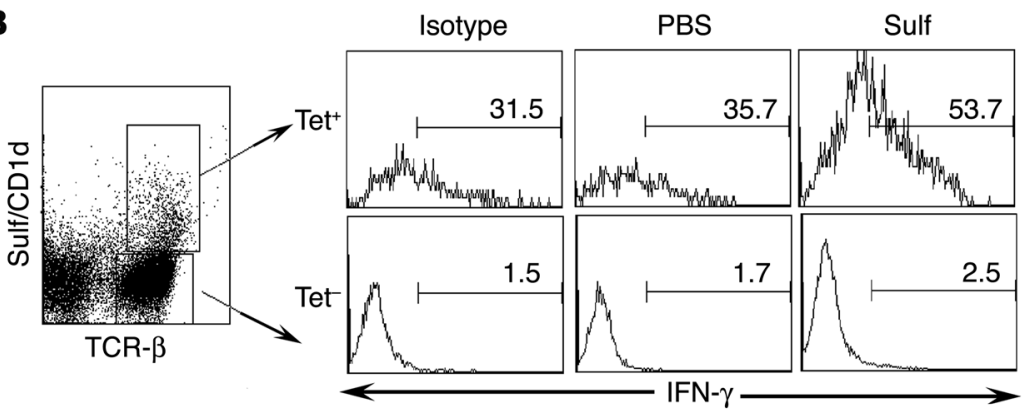

C
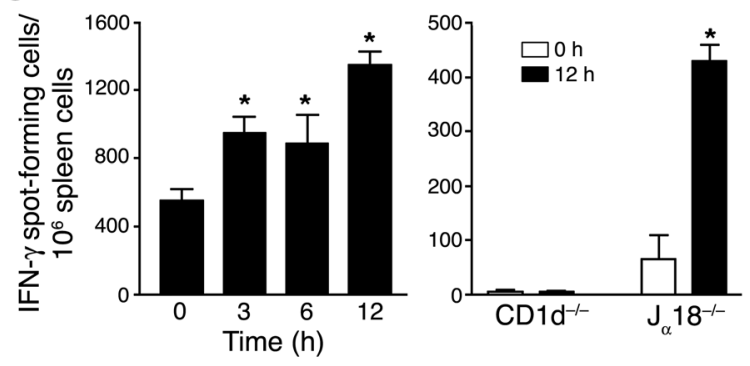

D
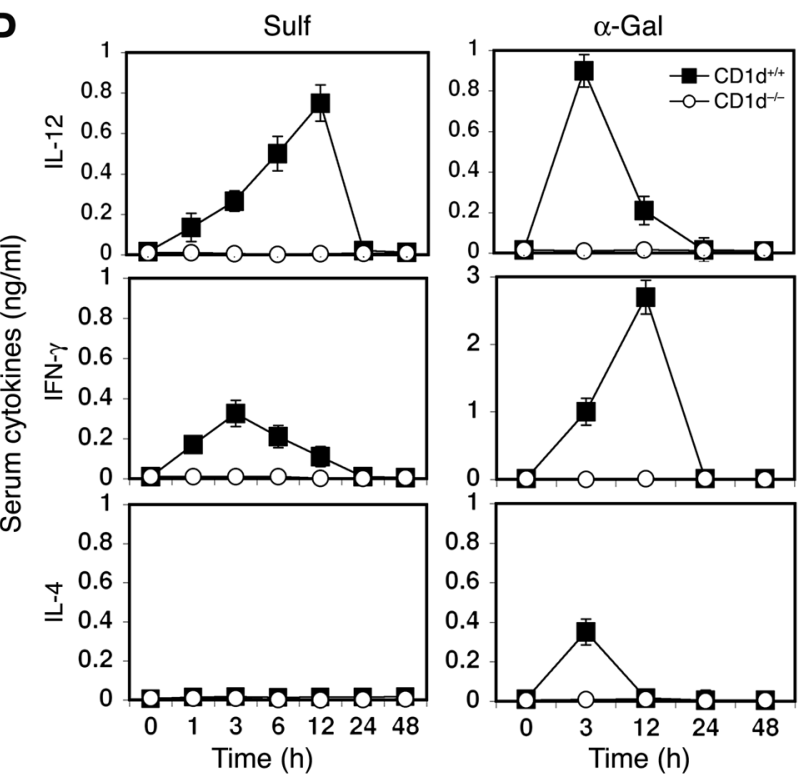

Adjuvant-free administration of sulfatide or its immunodominant species, cis-tetracosenoyl sulfatide, can either prevent or reverse antigen-induced EAE in $\mathrm{CD} 1 \mathrm{~d}^{+/+}$mice but not in $\mathrm{CD} 1 \mathrm{~d}^{-/-}$mice (ref. 23 and I. Maricic, unpublished observations). Although $\alpha$-GalCer, which binds with very high affinity to CD1d as well as to
Figure 1

Activation of type II NKT cells and cytokine secretion following sulfatide injection. (A) Flow cytometric profile of liver MNCs isolated at the indicated times from groups of C57BL/6 mice $(n=2$ per group) injected i.p. with $20 \mu \mathrm{g}$ sulfatide (Sulf), $2 \mu \mathrm{g} \alpha$-GalCer $(\alpha$-Gal), or PBS alone. Two-color staining was performed using sulfatide/CD1d tetramers and anti-TCR- $\beta$. Numbers within boxes indicate percent positive cells in total liver lymphocytes. (B) Tri-color flow cytometric analysis of IFN $-\gamma^{+}$cells in liver 3 hours after sulfatide injection. IFN- $\gamma^{+}$cells in sulfatide/CD1d tetramer ${ }^{+}$ $\left(\mathrm{Tet}^{+}\right)$or tetramer cells are shown. Numbers above brackets indicate percent positive cells. (C) ELISPOT analysis of splenocytes isolated at the indicated times from CD1d $\mathrm{d}^{+/+}, \mathrm{CD}_{1} \mathrm{~d}^{-/-}$, or $J_{\alpha} 18^{-/-}$mice following injection with sulfatide or PBS. ${ }^{*} P<0.002$. (D) Serum cytokine levels in $\mathrm{CD} \mathrm{d}^{+/+}$and $\mathrm{CD} 1 \mathrm{~d}^{-/-}$mice were examined at the indicated time points following sulfatide or $\alpha$-GalCer injection. Values are mean \pm SD. Data are representative of 3-4 individual experiments.

the invariant TCR (31), has been used to study the activation of NKT cells, to our knowledge, the consequences following their activation with self glycolipids have not been investigated. Here we have followed the dynamics of the immune cascade in liver following recognition of the self glycolipid sulfatide by type II NKT cells. Activation of sulfatide-reactive type II NKT cells resulted in preferential activation of plasmacytoid DCs (pDCs) and led to an IL-12- and MIP-2-dependent rapid recruitment of iNKT cells into mouse liver. Recruited iNKT cells became anergized, thereby preventing the induction of ConA-induced hepatitis. Following interaction with type II NKT cells, hepatic DCs from IL-12+/+ but not IL-12- $/$ mice adoptively transferred anergy to iNKT cells in recipients. These data illustrate a unique pathway of cellular interaction leading to type II NKT/pDC-mediated regulation of iNKT cells, which has important implications for potential therapeutic approaches in inflammatory diseases, including autoimmune diseases, asthma, and antitumor immunity, in which iNKT cells have been shown to be substantially involved.

\section{Results}

Hepatic activation of type II NKT cells results in selective serum cytokine increase. Accumulation of NKT cells in liver has allowed us to examine their activation and cytokine secretion following recognition of a self glycolipid. Following injection of sulfatide into mice, the percentage of hepatic sulfatide/CD1d tetramer ${ }^{+}$cells began to increase within 1 hour, peaked around 3 hours (3-fold that of background), and returned to the background level by 24 hours (Figure 1A). A more pronounced staining of these 

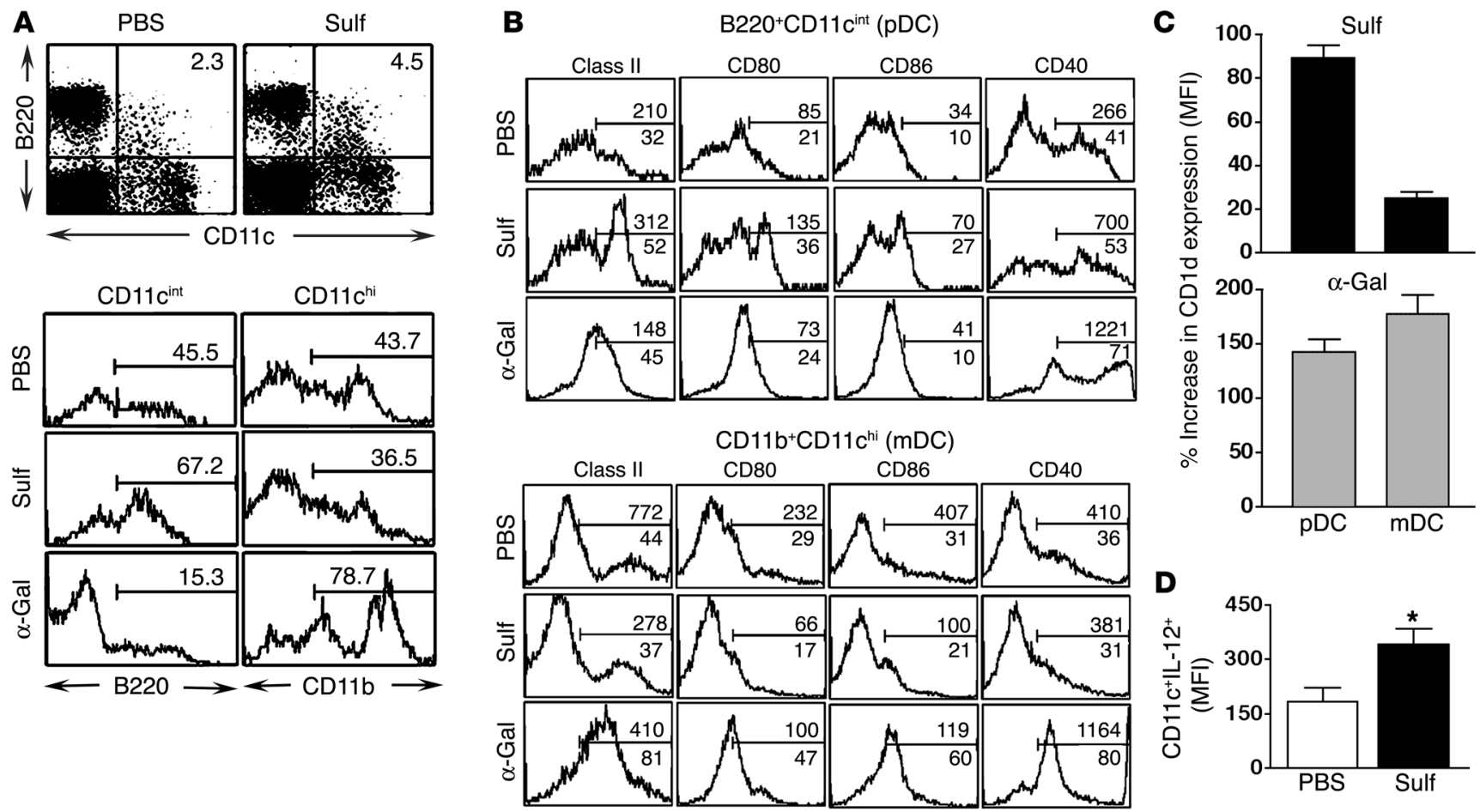

E

PDCA-1+CD11 $\mathrm{c}^{+}(\mathrm{pDC})$
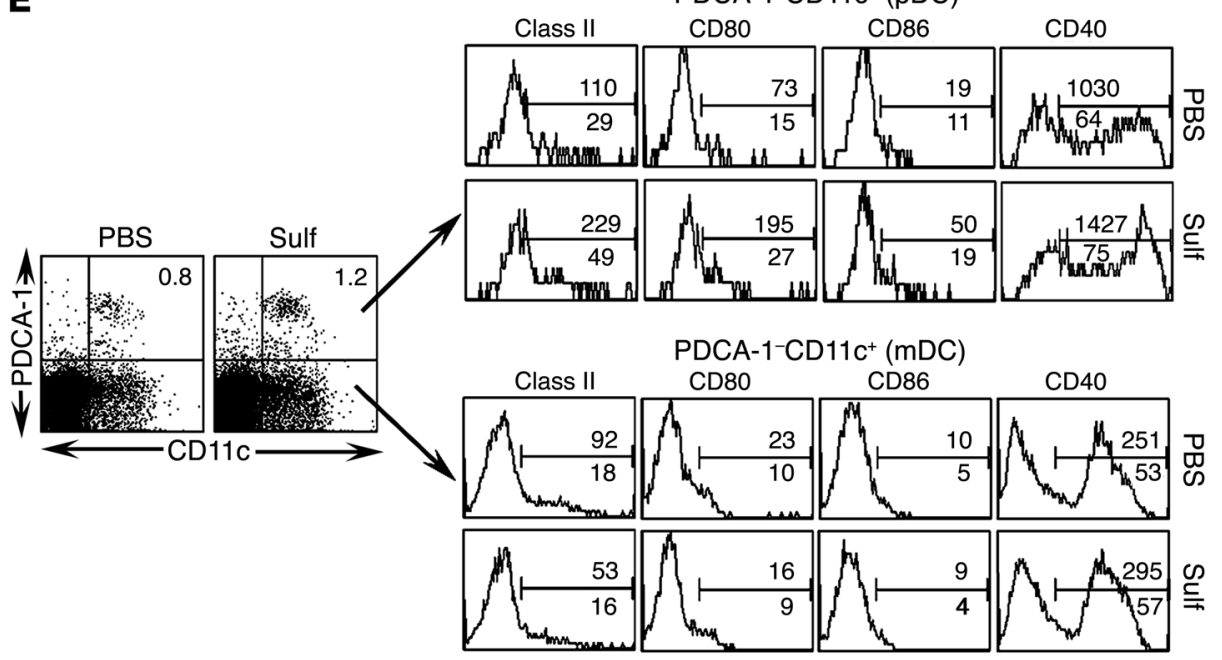

Figure 2

Selective activation of hepatic pDCs following sulfatide recognition. (A) Flow cytometric analysis of hepatic pDCs $\left(B 220+C D 11 \mathrm{c}^{+}\right) 3 \mathrm{hours}$ following sulfatide, $\alpha$-GalCer, or PBS injection. Dot plots are gated on whole MNCs; histogram plots are gated CD11 cint and CD11 $\mathrm{ch}^{\text {hi }}$ populations. Numbers within plots and above brackets indicate percent positive cells. (B) Flow cytometric analysis of costimulatory molecules on hepatic purified CD11C+DCs 12 hours following sulfatide, $\alpha$-GalCer, or PBS injection. Gated populations were analyzed for anti-I-A (class II), anti-CD80 (B7.1), anti-CD86 (B7.2), and anti-CD40. Histogram plots are gated on B220 ${ }^{+} \mathrm{CD} 11 \mathrm{c}^{\text {int }}(\mathrm{pDC})$ or $\mathrm{CD} 11 \mathrm{~b}{ }^{+} \mathrm{CD} 11 \mathrm{c}^{\mathrm{hi}}(\mathrm{mDC})$ populations. The marker was set up using isotype-matched control Ab. Numbers above brackets indicate MFI; numbers below brackets indicate percent positive cells. (C) Percent change in MFI of CD1d expression on pDCs and mDCs 12 hours following sulfatide or $\alpha$-GalCer injections in comparison to PBS-injected group. (D) MFI of IL-12 cytokine secreted by hepatic purified CD11C+ DCs 3 hours following sulfatide injection. ${ }^{*} P<0.002$. (E) Tri-color flow cytometric analysis of pDCs isolated from sulfatide-injected mice as in B. Liver MNCs were stained with allophycocyanin-conjugated anti-mouse PDCA-1 and PE-conjugated CD11c. Numbers above brackets indicate MFI; numbers below brackets and within plots indicate percent positive cells. Data are representative of $2-3$ individual experiments.

T cells with the sulfatide/CD1d tetramer even at 24 hours (increase in mean fluorescence intensity [MFI] from 385.8 in PBS to 579.5 in the sulfatide-treated group) suggests that they maintain their state of activation and do not downregulate their TCRs. As expect- ed, sulfatide-reactive $\mathrm{T}$ cells remained unchanged in number and in their state of activation following $\alpha$-GalCer or PBS injection (Figure 1A). On the other hand, there was a marked increase in sulfatide/CD1d tetramer ${ }^{+} \mathrm{IFN}-\gamma^{+}$cells in sulfatide-injected mice 
A
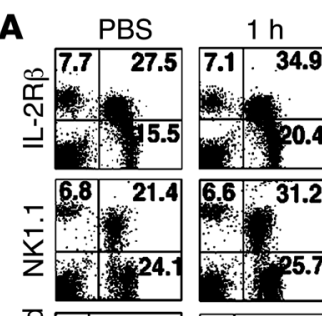

$3.8 \mathrm{~h}$

$6 \mathrm{~h} \quad 12 \mathrm{~h}$

$24 \mathrm{~h}$
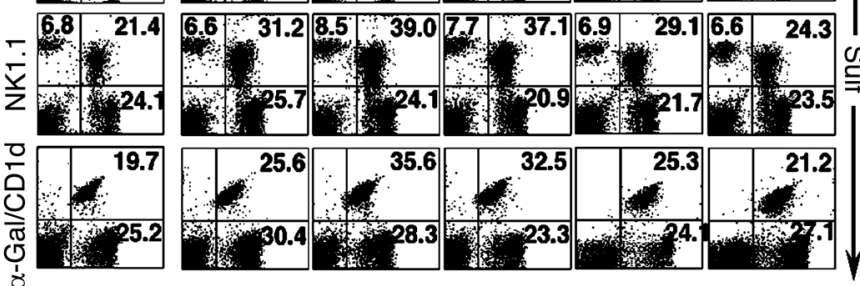

\begin{tabular}{ll}
8.5 & 28.3 \\
\hline
\end{tabular}
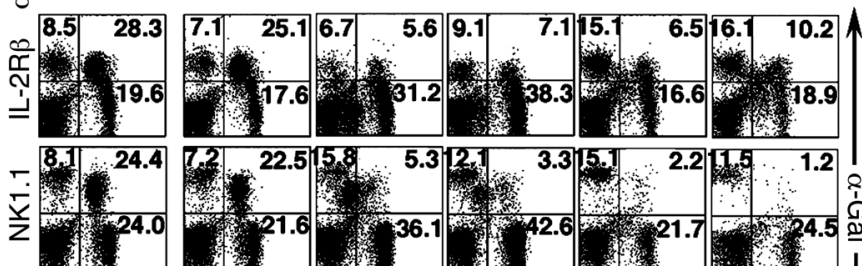

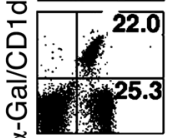
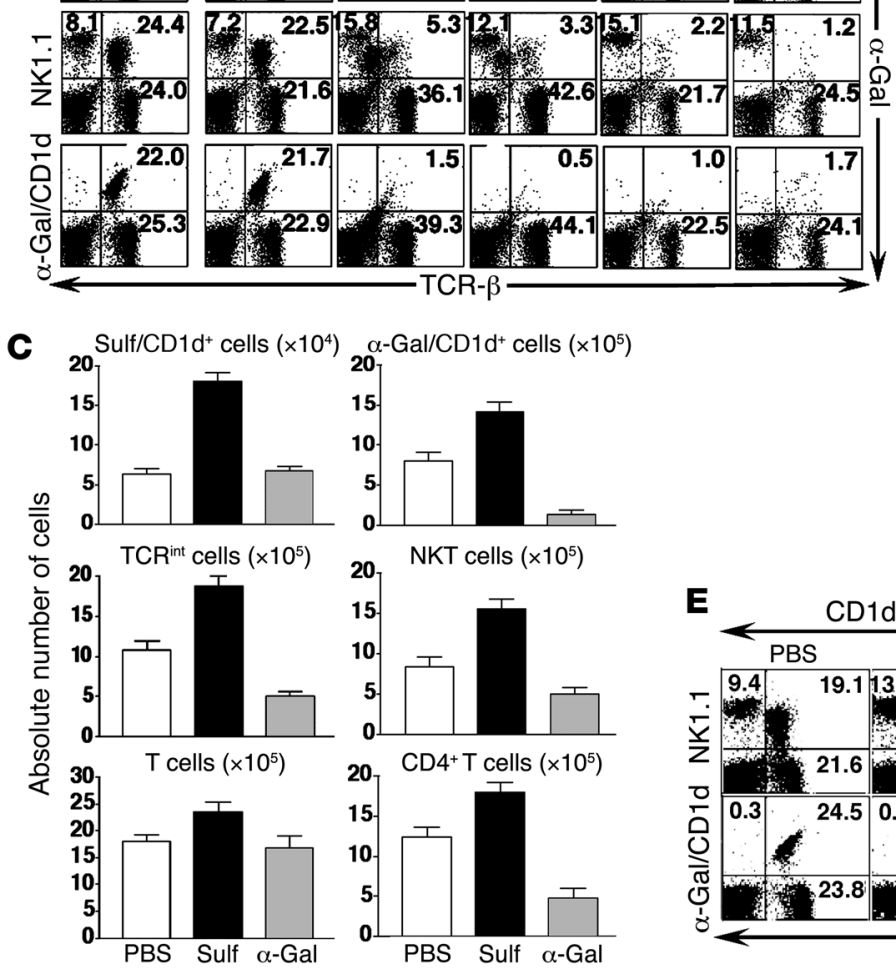
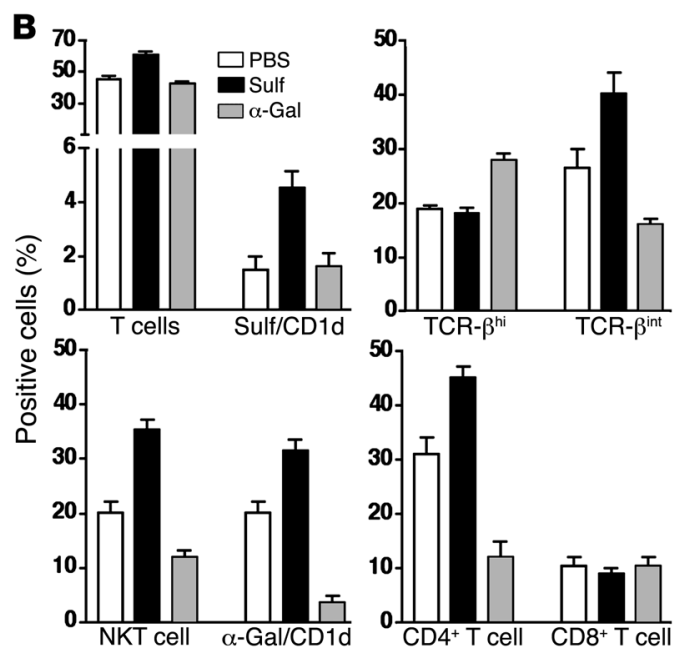

D
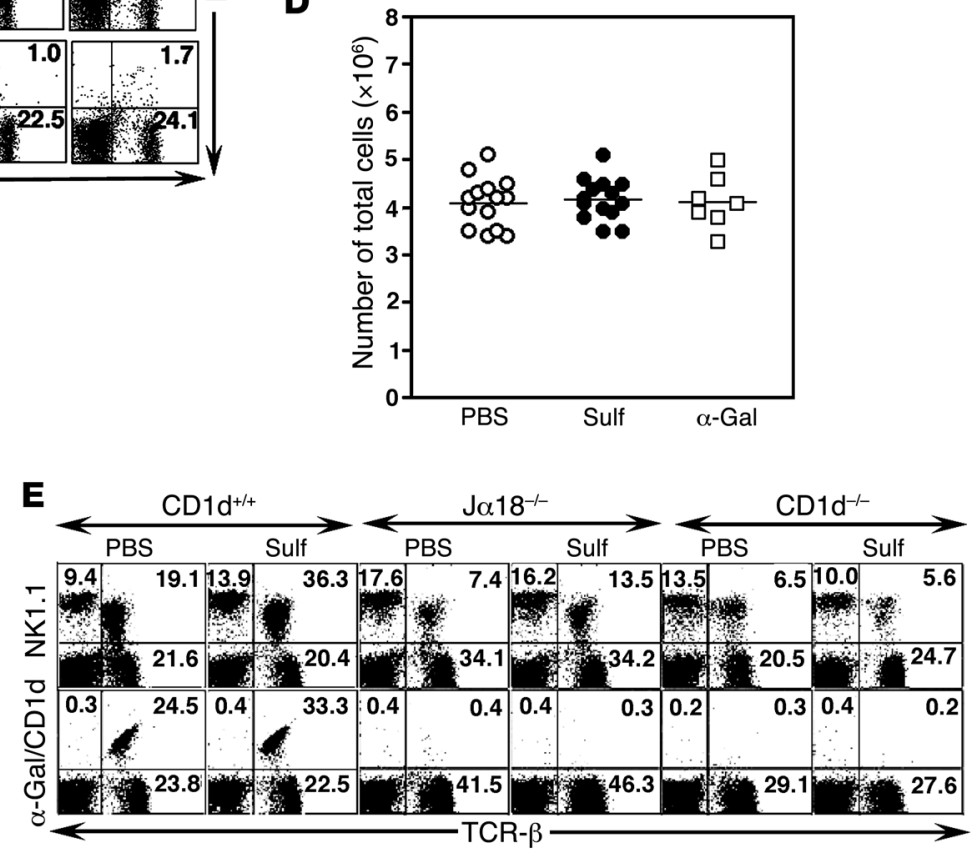

Figure 3

Sulfatide-induced CD1d-dependent recruitment of iNKT cells into liver. (A) Flow cytometric analysis of liver MNCs isolated at the indicated times from groups of C57BL/6 mice ( $n=2$ per group) injected i.p. with $20 \mu \mathrm{g}$ sulfatide, $2 \mu \mathrm{g} \alpha$-GalCer, or PBS alone. Two-color staining was performed using anti-IL-2R $\beta$, anti-NK1.1, $\alpha$-GalCer/CD1d, and anti-TCR- $\beta$, and cells were analyzed by flow cytometry. Numbers in quadrants indicate percent positive cells in total liver lymphocytes. (B) Summary of percent positive cells in each group from A and Figure 1A (mean \pm SD). (C) Absolute number of various lymphocyte subsets in liver. (D) Total number of liver MNCs 3 hours following sulfatide, $\alpha$-GalCer, or PBS injection. Horizontal bars indicate mean values of 14 mice in each PBS- and sulfatide-injected group and of 7 mice in $\alpha$-GalCer-injected group. (E) Flow cytometric analysis of liver MNCs at 3 hours following injection of sulfatide or PBS into CD1 $\mathrm{d}^{+/+}, \mathrm{CD}_{1} \mathrm{~d}^{-/-}$, or $\mathrm{J}_{\alpha} 18^{-/-}$mice. Numbers in quadrants indicate percent positive cells. Data are representative of $4-5$ individual experiments.

compared with PBS-injected mice (53.7\% versus $35.7 \%$; Figure $1 \mathrm{~B}$ ). To further examine the CD1d-dependent and iNKT-independent activation of sulfatide-reactive $T$ cells, enzyme-linked immunosorbent spot (ELISPOT) analysis was carried out on splenocytes from $\mathrm{CD} 1 \mathrm{~d}^{+/+}, \mathrm{J}_{\alpha} 18^{-/-}$, and $\mathrm{CD} 1 \mathrm{~d}^{-/-}$mice injected with sulfatide or vehicle. As shown in Figure 1C, the frequency of IFN- $\gamma$-secreting cells significantly increased (2- to 3 -fold) following sulfatide injection in $\mathrm{CD} 1 \mathrm{~d}^{+/+}$and $\mathrm{J}_{\alpha} 18^{-/-}$mice, but not in $\mathrm{CD} 1 \mathrm{~d}^{-/-}$mice. These data clearly indicate that sulfatide-reactive non-iNKT cells are activated and secrete cytokines following recognition of the self-glycolipid and that this is dependent upon the presence of CD1d molecules and independent of the presence of iNKT cells.

Next we determined whether activation of sulfatide-reactive type II NKT cells results in an increase in serum cytokine levels. As shown in Figure 1D, levels of IL-12 (p40/p70) and IFN- $\gamma$, but not IL-4, were markedly increased in CD $1 \mathrm{~d}^{+/+}$mice, but not CD $1 \mathrm{~d}^{-/-}$mice, that were injected with sulfatide. Serum IL-12 levels peaked earlier with $\alpha$-GalCer (3 hours) than with sulfatide injection (12 hours). 
A
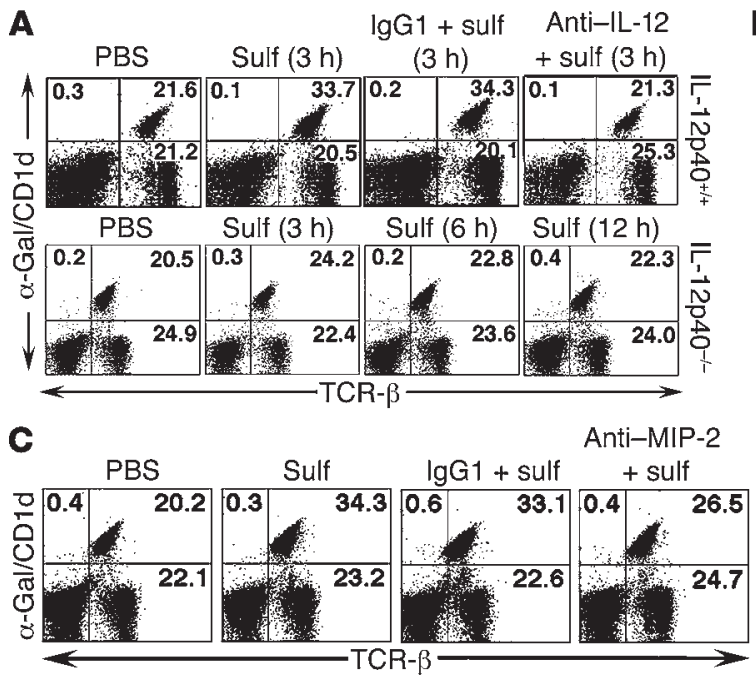

B

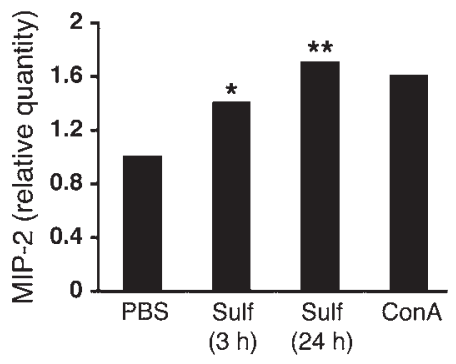

D

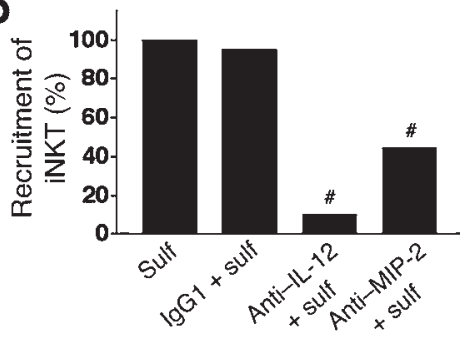

Figure 4

Involvement of IL-12 and MIP-2 in sulfatide-induced recruitment of iNKT cells. (A) Flow cytometric analysis of liver MNCs isolated at the indicated times from groups of IL-12p40 $40^{+/+}$and IL-12p $40^{-/-}$mice injected i.p. with $20 \mu \mathrm{g}$ sulfatide or PBS alone. Groups of IL-12p40+/+ mice also received a neutralizing dose of anti-IL-12 or control IgG1 24 hours before injection with sulfatide. Two-color staining was performed using $\alpha$-GalCer/CD1d tetramers and anti-TCR- $\beta$ mAbs. Numbers in quadrants indicate percent positive cells in total liver lymphocytes. (B) Real-time PCR analysis of mRNA isolated from liver tissues at the indicated times after injection in sulfatide- compared with PBS-treated mice. ${ }^{*} P<0.02$, ${ }^{* *} P<0.009$ versus PBS. ConA-stimulated splenocytes were used as a control. (C) Flow cytometric analysis of liver MNCs isolated from groups of C57BL/6 mice injected i.p. with $20 \mu \mathrm{g}$ sulfatide or PBS alone. Groups of mice also received a neutralizing dose of anti-MIP-2 or control IgG1 24 hours before injection with sulfatide. Analysis was performed as in $\mathbf{A}$. Numbers in quadrants indicate percent positive cells in total liver lymphocytes. (D) Recruitment of iNKT cells into liver following sulfatide injection alone or in combination with anti-IL-12, anti-MIP-2, or isotype-matched IgG1 control antibodies. ${ }^{\#}<0.005$ versus sulfatide alone or sulfatide plus IgG1. Data are representative of $3-5$ individual experiments.

Although serum IL-12 levels were similar following injection with either lipid, IFN- $\gamma$ levels were 10-fold lower in mice injected with sulfatide compared with $\alpha$-GalCer. These data demonstrate a selective increase in serum cytokines IL-12 and IFN- $\gamma$ but not IL-4 following activation of sulfatide-reactive type II NKT cells.

Preferential activation of hepatic $p D C$ s during type II NKT cell activation. Because DCs are known to secrete IL-12 upon activation, we examined activation of hepatic pDCs and myeloid DCs (mDCs) (32) following type II NKT activation. A marked increase occurred in pDCs $\left(\mathrm{B} 220^{+} \mathrm{CD} 11 \mathrm{c}^{\text {int; }}\right.$ Figure $\left.2 \mathrm{~A}\right), \mathrm{B} 220^{+} \mathrm{CD} 11 \mathrm{c}^{\text {int }}$ cells (Figure $\left.2 \mathrm{~A}\right)$, and PDCA $1^{+} \mathrm{CD} 11 \mathrm{c}^{+}$cells (Figure 2E), but not $\mathrm{mDCs}\left(\mathrm{CD} 11 \mathrm{c}^{\mathrm{hi}} \mathrm{CD} 11 \mathrm{~b}^{+}\right.$; Figure $2 \mathrm{~A}$ ) or PDCA-1-CD11 $\mathrm{c}^{+}$cells (Figure $2 \mathrm{E}$ ), following sulfatide-reactive type II NKT cell activation. In contrast, a marked reduction in the number of $\mathrm{pDCs}$ and an increase in the number of mDCs $\left(\mathrm{CD} 11 \mathrm{c}^{\mathrm{hi}} \mathrm{CD} 11 \mathrm{~b}^{+}\right)$followed iNKT activation with $\alpha$-GalCer (Figure 2A). These data suggest that sulfatide and $\alpha$-GalCer may target different DC populations in the liver, and in particular that pDCs are prominently affected following activation of type II NKT cells. This differential pattern of activation was also reflected in the upregulation of costimulatory molecules including MHC class II, CD80, CD86, and CD1d on pDCs and mDCs following sulfatide or $\alpha$-GalCer injection (Figure 2, B and E). Interestingly, CD40 expression on pDCs increased in both cases, whereas it was upregulated on mDCs following injection with $\alpha$-GalCer but not sulfatide. There was no detectable stimulation of either DC population in cytometry at 3 hours (Figure 3A) Because activation of iNKT cells with $\alpha$-GalCer results in downmodulation of TCR and apoptosis. A summary of the changes in percentage and in absolute number of $\alpha$-GalCer/CD1d tetramer ${ }^{+}$and sulfatide/CD1d tetramer ${ }^{+}$ cells among PBS-, sulfatide-, and $\alpha$-GalCer-injected mice is shown in Figure 3, B and C, respectively. However, there was no change in the total number of cells among the 3 groups (Figure 3D). There was no significant activation of NK cells (NK1.1 ${ }^{+}$TCR $\left.-\beta^{-}\right)$, B cells (B220+TCR- $\left.\beta^{-}\right)$, or classical T cells (NK1.1-TCR- $\beta^{+}$) in sulfatide-injected mice (data not shown). The CD1d dependence was demonstrated by the absence of increase in either type of NKT cell in $\mathrm{CD} 1 \mathrm{~d}^{-/-}$mice (Figure 3E). An increase in NK1.1 $1^{+} \mathrm{TCR}-\beta^{+}$cells in $\mathrm{J}_{\alpha} 18^{-/-}$mice following sulfatide injection (Figure $3 \mathrm{E}$ ) indicated expansion of type II NKT cells in the absence of iNKT cells.

Involvement of IL-12 and MIP-2 in sulfatide-mediated recruitment of iNKT cells into liver. To examine the possible role of cytokines in the recruitment of lymphocytes into liver, we initially focused on IL-12 secretion by hepatic DCs. As shown in Figure 4, A and D, hepatic recruitment of iNKT cells did not occur in mice injected with antiIL-12 mAb or in IL-12p $40^{-/-}$mice at the time points examined. An isotype-matched control $\mathrm{Ab}$ had no effect on the recruitment. Next we examined the role of MIP-2 by RNAase protection assay (RPA), RT-PCR (data not shown), and real-time PCR analysis (Figure 4B) of liver tissues at the indicated time points and found a significant increase in the expression of MIP-2 following sulfatide injection. No 
A
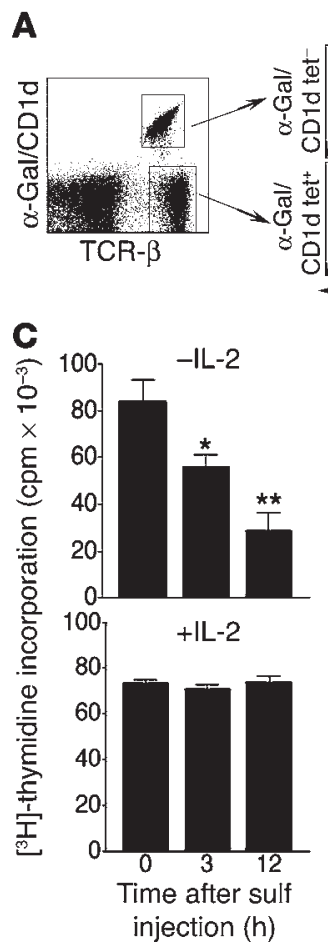

Isotype

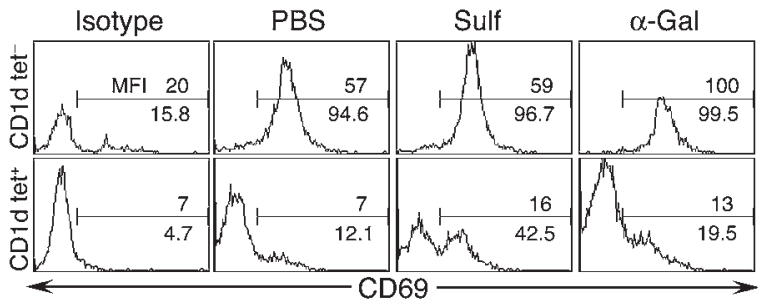

D

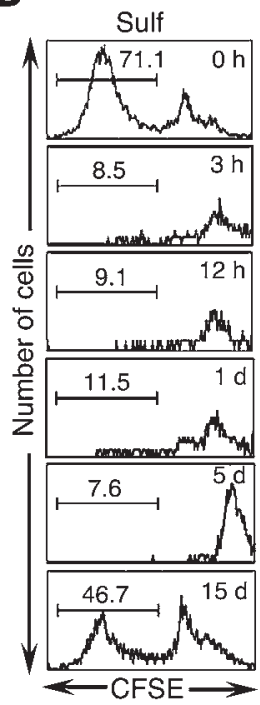

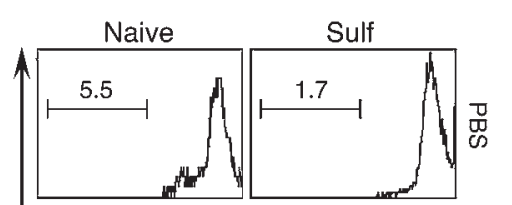
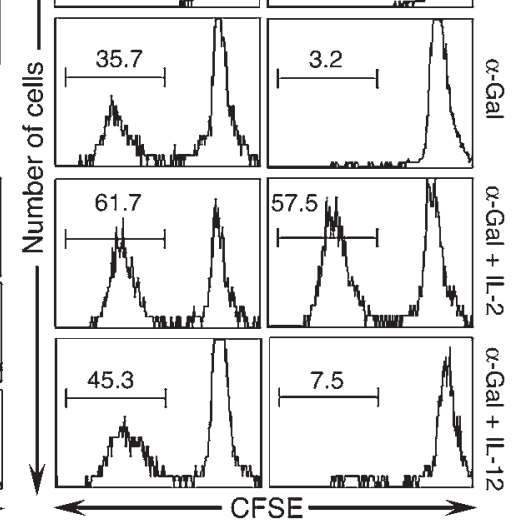

B

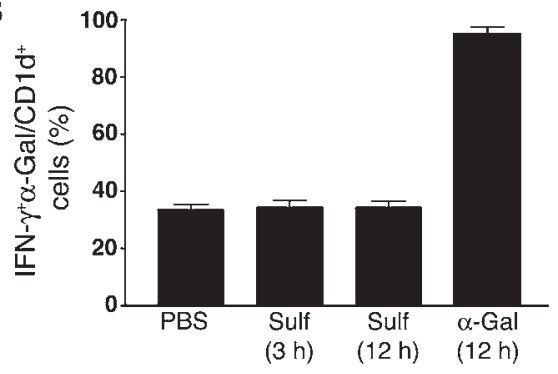

E

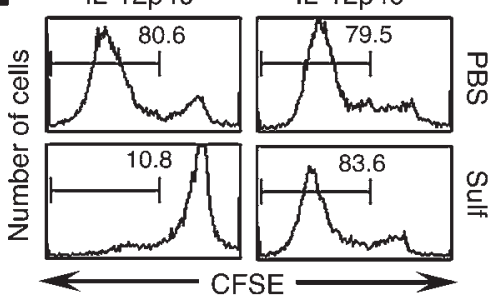

Figure 5

Anergy induction in the iNKT population. (A) Tri-color flow cytometric profiles of liver MNCs isolated 3 hours following sulfatide, $\alpha$-GalCer, or PBS injection. CD69 expression in $\alpha$-GalCer/CD1d tetramer+ or tetramer populations is shown. Numbers above brackets indicate MFI; numbers below brackets indicate percent positive cells. (B) IFN- $\gamma^{+} \alpha$-GalCer/CD1d tetramer ${ }^{+}$cells in total liver lymphocytes at the indicated times following sulfatide, $\alpha$-GalCer, or PBS injection. (C) Incorporation of $\left[{ }^{3} \mathrm{H}\right]$-thymidine in triplicate cultures of splenocytes in response to in vitro challenge with $\alpha$-GalCer $(10 \mathrm{ng} / \mathrm{ml})$ in the absence or presence of IL-2 $(5 \mathrm{ng} / \mathrm{ml})$. Splenocytes were isolated from mice 3 and 12 hours after sulfatide injection. ${ }^{\star} P<0.002,{ }^{* *} P<0.001$ versus 0 hours. (D) CFSE dilution profile of $\alpha$-GalCer/CD1d tetramer ${ }^{+}$(iNKT) cells in splenocytes isolated at the indicated time points from sulfatide- or PBS-injected mice. Splenocytes were labeled with CFSE and stimulated with $\alpha$-GalCer in vitro in the presence or absence of IL-2. IL-12 served as a control. (E) CFSE dilution analysis of hepatic $\alpha$-GalCer/CD1d tetramer ${ }^{+}$cells in response to in vitro stimulation with $\alpha$-GalCer from IL-12p40+/+ and IL-12p40-/- mice injected with sulfatide or PBS. Numbers above brackets in $\mathbf{D}$ and $\mathbf{E}$ indicate percent positive cells. Data are representative of 3-4 individual experiments.

significant increase in the expression of the chemokines RANTES, MIP-1 $\beta$, MIP-1 $\alpha$, IP-10, MCP-1, and TCA3 was detected by the RPA assays (data not shown). Treatment of mice with neutralizing antiMIP-2 antibody, but not with an isotype-matched control, resulted in significant inhibition of recruitment of iNKT cells (Figure 4, C and D). These data support the important role of both IL-12 and MIP-2 in the recruitment of iNKT cells into liver.

Recruited $i N K T$ cells are not activated, but are anergized. To investigate the possibility of bystander activation of hepatic memory-like iNKT cells caused by activation of pDCs and type II NKT cells, we examined their upregulation of the early activation marker CD69 and cytokine secretion. As shown in Figure 5A, while CD69 was markedly upregulated on iNKT cells following injection of $\alpha$-GalCer, no marked increase occurred in percent or MFI of $\alpha$-GalCer/CD1d tetramer ${ }^{+}$cells in sulfatide- or PBS-injected mice. Sulfatide injection caused increased CD69 expression within the non-iNKT population (Figure 5A), indicating their activation, but did not increase IFN- $\gamma^{+} \alpha-$ GalCer/CD1d tetramer ${ }^{+}$cells (Figure 5B). In contrast, injection of $\alpha$-GalCer resulted in $100 \%$ of the $\alpha$-GalCer/CD1d tetramer ${ }^{+}$cells staining for IFN- $\gamma$ secretion. Collectively, these data show that recruited iNKT cells are not activated following sulfatide injection.

We next examined whether the recruited iNKT cells are anergized by assessing their proliferation in response to an in vitro challenge with $\alpha$-GalCer in the presence or absence of IL-2. Our results showed a significant inhibition of proliferation to $\alpha-G a l C e r(>70 \%)$ that was reversed by the addition of IL-2 in cultures from sulfatide-treated mice (Figure 5C). Similarly, the CFSE dilution profile of $\alpha$-GalCer/ CD1d tetramer ${ }^{+}$cells showed a complete inhibition of proliferation in response to $\alpha$-GalCer stimulation in vitro within 3 hours that continued until day 5 and recovered by 2 weeks, and this CFSEdetected inhibition of iNKT cell proliferation was reversed by the addition of IL-2 but not IL-12 (Figure 5D). Next we examined the role of IL-12 in the induction of anergy in iNKT cells in vivo. The loss of anergy induction following activation of type II NKT cells observed in IL-12p40-/- mice (Figure 5E) clearly indicates a requirement for IL-12 in the anergy induction in iNKT cells in vivo.

Adoptive transfer of hepatic DCs from sulfatide-injected $I L-12 p 40^{+/+}$ but not IL-12p40--- mice can induce anergy in the recipient's iNKT cells. Hepatic DCs should play a crucial role in the activation or inacti- 


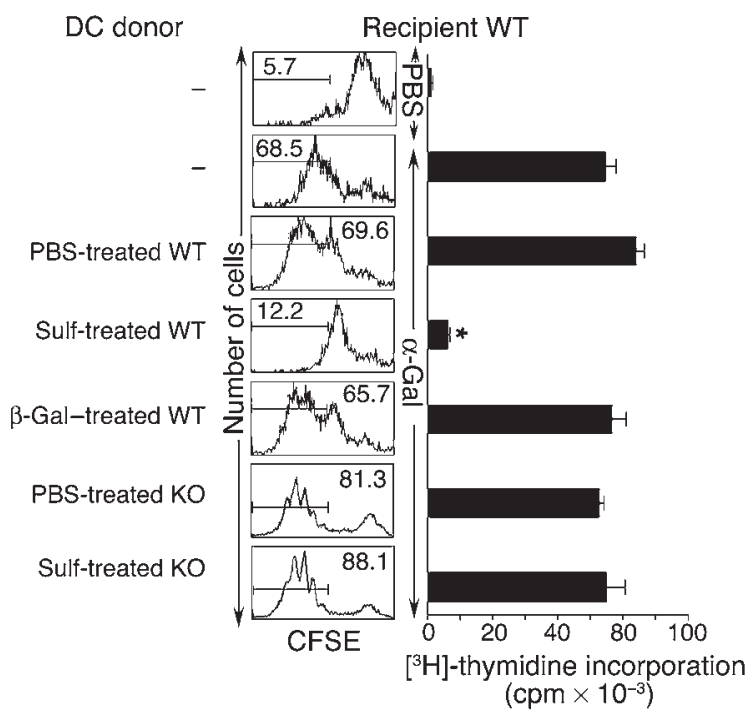

vation of NKT cells. We examined whether iNKT cell anergy can be induced by hepatic CD $11 c^{+}$DCs that have been rendered tolerogenic following the activation of sulfatide-reactive type II NKT cells. At the same time, we also examined the role of IL-12 secretion by DCs in anergy induction. Liver $\mathrm{CD} 11 \mathrm{c}^{+} \mathrm{DCs}$ purified from IL- $12 \mathrm{p} 40^{+/+}$or IL-12p $40^{-/-}$mice injected with sulfatide-, $\beta$-GalCer-, or PBS were adoptively transferred into naive recipients. As shown in Figure 6, complete inhibition of proliferation (CFSE dilution and thymidine incorporation) of iNKT cells in response to $\alpha$-GalCer was found in the recipients of DCs from sulfatide-injected mice. In contrast, proliferation of iNKT cells was not inhibited in recipients of DCs from PBS- or $\beta$-GalCer-injected mice. No inhibition of proliferation was detected when DCs were transferred from sulfatide-treated IL-12p40-/- mice compared with PBS-treated IL-12 $440^{-/-}$mice. These results clearly showed that iNKT cell anergy is mediated by hepatic DCs rendered tolerogenic following activation of type II NKT cells and that IL-12 secretion by DCs plays a crucial role in the anergy induction.

Administration of sulfatide prevents ConA-induced hepatitis. Because ConA-induced liver damage is mediated by iNKT cells (6-8), we have used this model of liver disease to examine one consequence of the functional inactivation of iNKT cells in vivo. As shown in Figure 7A, serum elevation of alanine aminotransferase (ALT) and aspartate aminotransferase (AST) in response to ConA injection was significantly reduced in sulfatide-treated mice compared with mice without sulfatide treatment. Histological examination showed diffuse and massive infiltration and severe necrosis in control mice that was significantly reduced in sulfatide-treated animals (Figure 7B). Similarly, at a macroscopic level, the white spots indicative of severe necrosis observed following ConA injection were absent in sulfatide-treated IL- $12 \mathrm{p} 40^{+/+}$mice (Figure $7 \mathrm{C}$ ). Notably, loss of anergy induction in IL-12p40-/- mice correlated with the loss of sulfatide-mediated protection from ConA-induced liver disease, as assessed by liver morphology and liver enzymes (Figure 7, C and D). These data clearly indicate that IL-12-dependent, sulfatide-induced anergy of iNKT cells is the key mechanism in the prevention of ConA-induced hepatitis.

Sulfatide-mediated inbibition of effector pathways is a key mechanism of protection from liver damage. In order to determine the mechanism by which inactivated iNKT cells prevent ConA-induced liver dam-

\section{Figure 6}

Adoptive transfer of hepatic DCs from sulfatide-treated IL-12p40+/+ mice, but not from IL-12p40-/- mice, induces anergy in iNKT cells in recipients. Shown are CFSE dilution and $\left[{ }^{3} \mathrm{H}\right]$-thymidine incorporation of splenocytes in response to in vitro challenge with $\alpha$-GalCer in recipient WT (IL-12p40+/+) mice. Groups of WT or KO (IL-12p40-/-) mice ( $n=10$ per group) were injected with sulfatide, $\beta$-GalCer, or PBS. One day later, purified liver CD11 $\mathrm{C}^{+}$DCs $\left(4-5 \times 10^{5}\right)$ from donor mice were injected i.v. into WT recipients. Two days later, splenocytes were assayed for in vitro proliferation to $\alpha-G a l C e r$, and analysis was performed as in Figure 5, C and D. Numbers above brackets indicate percent positive cells. ${ }^{*} P<0.001$ in sulfatide-treated WT groups versus PBS-treated WT, $\beta$-GalCer-treated WT, and sulfatide-treated IL-12 KO groups. Data are representative of $2-3$ individual experiments.

age, we examined important effector pathways, including serum cytokine bursts, neutrophil recruitment into liver, and apoptosis of NK and NKT cells $(8,33)$. As shown in Figure 8A, ConA-induced serum cytokine levels of IFN- $\gamma$, IL-12, TNF- $\alpha$, and IL-4 were considerably inhibited in sulfatide-treated mice. Similarly, the ConAinduced influx of neutrophils into the liver was significantly inhibited in sulfatide-treated mice (Figure 8, B and C). In addition, there was a marked decrease in annexin $\mathrm{V}^{+}$NKT cells and a complete absence of annexin $\mathrm{V}^{+} \mathrm{NK}$ cells in sulfatide-treated mice (Figure $8 D$ ). A summary of the percentage of annexin- $\mathrm{V}^{+}$NKT and NK cells is shown in Figure 8E. These data clearly indicate inhibition of the apoptosis of NK and NKT cells in sulfatide-treated mice.

\section{Discussion}

Recognition of CD1-bound self glycolipids by NKT cells is crucial in the rapid activation of innate-like immunity, with important consequences for the adaptive immune response. Here we describe what we believe to be a novel mechanism of cellular interactions in the liver among distinct CD1d-restricted NKT cell populations and DCs and its potential role in the induction of tolerance in hepatic inflammation. Our data show that activation of sulfatidereactive type II NKT cells and pDCs in the liver leads to a rapid recruitment of iNKT cells that become anergic and are able to block inflammatory liver disease (34).

Activation of iNKT cells using the foreign glycolipid $\alpha$-GalCer, which binds with very high affinity to CD1d as well as the invariant TCR (31), leads to rapid cytokine secretion, TCR downregulation, and apoptosis $(12,16-19)$. In contrast, following recognition of the self glycolipid sulfatide, a subset of CD1d-restricted type II NKT cells are activated without any significant downregulation of their TCRs or apoptosis. Whether iNKT cells also behave in a similar fashion following activation with self-glycolipid ligands such as iGB3 is not known at present. What is known is that, unlike $\alpha$-GalCer, iGB3 does not activate iNKT cells upon i.v. injection, and $i G B 3 / C D 1 d$ tetramers do not stain iNKT cells (15). The immune cascade following iNKT activation with $\alpha$-GalCer that includes liver damage (17) and activation of NK cells, B cells, and other $\mathrm{CD}^{+}$and/or $\mathrm{CD}^{+} \mathrm{T}$ cells (35) did not follow activation of type II NKT cells with sulfatide; accordingly, no considerable liver damage or activation of B, NK, and T cells was found. These observations suggest that consequences following self-glycolipid recognition by both iNKT and type II NKT cells may be different from those initiated by $\alpha$-GalCer, which behaves more like a superantigen (36). The rapid recruitment of iNKT cells into liver following sulfatide injection described here mimicked their recruitment in a 
A

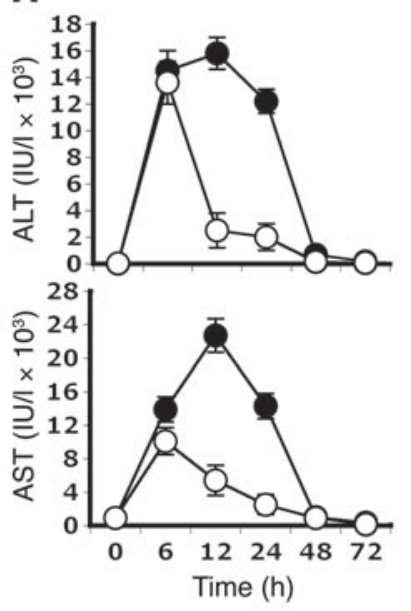

C
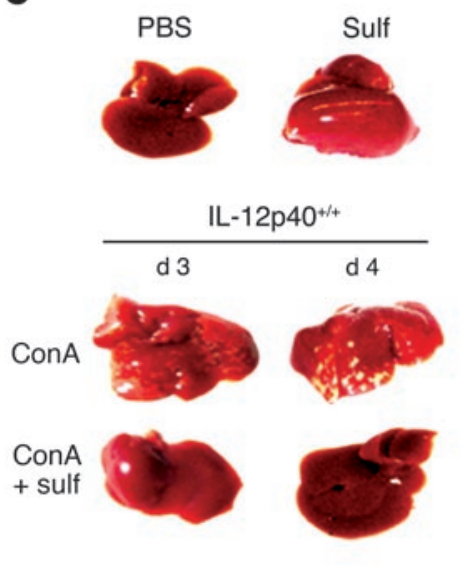

B PBS

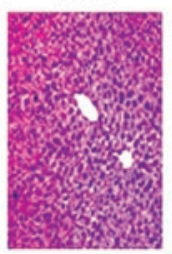

Sulf

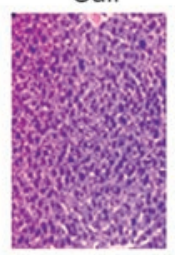

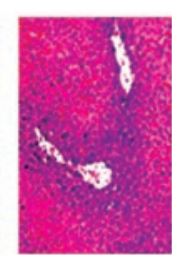

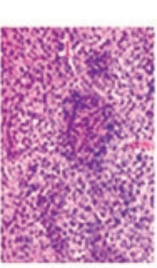

$12 \mathrm{~h}$

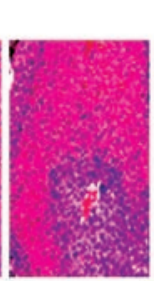

ConA

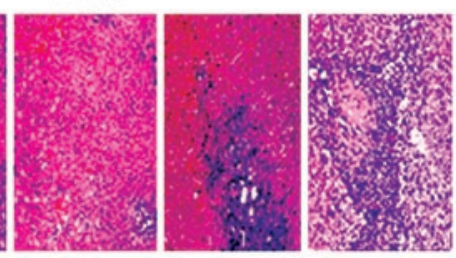

ConA + sulf

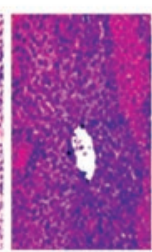

$24 \mathrm{~h}$

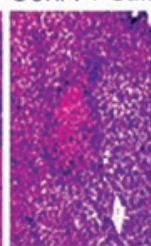

$48 \mathrm{~h}$

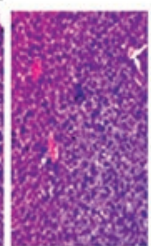

$72 \mathrm{~h}$

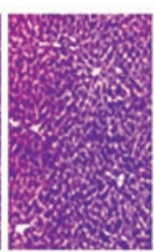

$96 \mathrm{~h}$

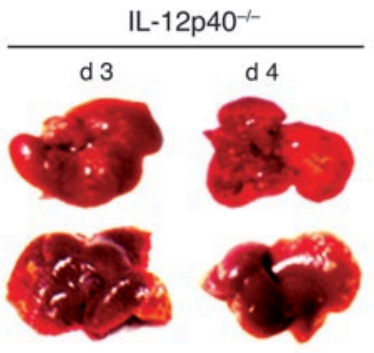

D

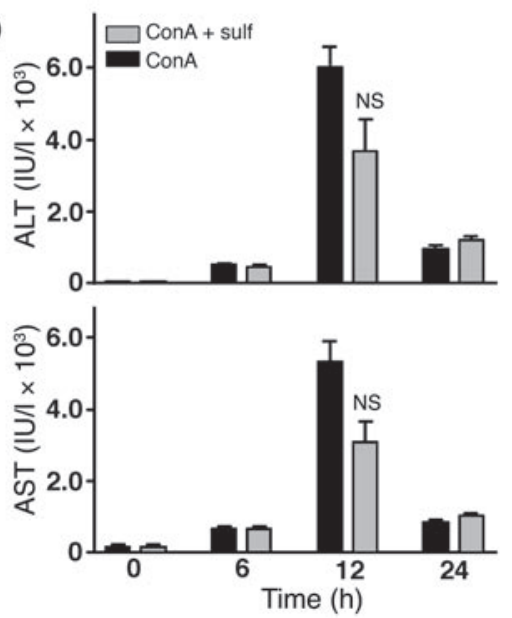

Figure 7

Sulfatide administration protects against ConA-induced hepatitis. (A) ALT and AST levels were examined in serum at different time points in IL-12p40+/+ mice injected with ConA (filled symbols) or ConA plus sulfatide (open symbols). Values are mean \pm SD of 5 mice per group. $P<0.001$ between groups. (B) Representative H\&E-stained liver sections of mice treated with ConA and ConA plus sulfatide. The bottom left image is from a control mouse injected with sulfatide only. Original magnification, $\times 200$. (C) Gross morphology of liver of ConA- and sulfatidetreated IL-12p40+/+ and IL-12p40-/- mice. Top panel shows control mice injected with PBS or sulfatide only. (D) ALT and AST levels in IL-12p40-/mice injected with ConA or ConA plus sulfatide. No significant difference between the 2 groups $(P \geq 0.75)$ was observed at the 12-hour time point. Data are representative of 3-4 individual experiments.

contact hypersensitivity model following skin sensitization (34). iNKT cells are activated during the hypersensitivity as a result of release of self glycolipids and activation of DCs. In contrast, iNKT cells were anergized in our experiments, which may relate to inefficient activation of DCs as well as the lack of release of self glycolipids specific for these NKT cells.

Although how the interaction of pDC and type II NKT cells results in the induction of anergy in iNKT cells is not precisely known, several observations indicate their nonresponsiveness to $\alpha$-GalCer: (a) lack of upregulation of the early activation marker CD69 (Figure 5A); (b) lack of cytokine secretion (Figure 5B); (c) absence of enhanced autologous killing against syngeneic thymocytes (data not shown); (d) failure to proliferate in response to $\alpha$-GalCer in vitro in the absence of exogenously added IL-2 (Figure 5, C and D, and Figure 6); and (e) inability to mediate ConA-induced liver damage (Figure 7, B and C, and data not shown). These data also highlight a nonreciprocity among NKT cell subsets: activation of sulfatide-reactive type II NKT cells affected the iNKT cell population, whereas type II NKT cells remained unaffected following activation of iNKT cells by $\alpha$-GalCer (Figure 1A). This may be the result of a functional difference among distinct NKT cell subsets or of involvement of myeloid versus lymphoid DC populations.

Distinct APC populations in liver can become involved during the presentation of glycolipids to distinct populations of NKT cells. Thus in the liver, it is primarily Kupffer cells, whereas in spleen, DCs are most effective in stimulating iNKT cells by $\alpha$-GalCer $(37,38)$. Interestingly, consistent with earlier findings (32), in liver activation of mDCs with concomitant downregulation of pDCs occurred following iNKT activation (Figure 2A). In contrast, primarily pDCs are activated following stimulation of type II NKT cells (Figure 2, A, B, and E). Our data suggest that presentation of sulfatide by pDCs to type II NKT cells results in a reciprocal activation of $\mathrm{pDCs}$, with release of IL-12, upregulation of MIP-2, and recruitment of iNKT cells into the liver. MIP-2 has 

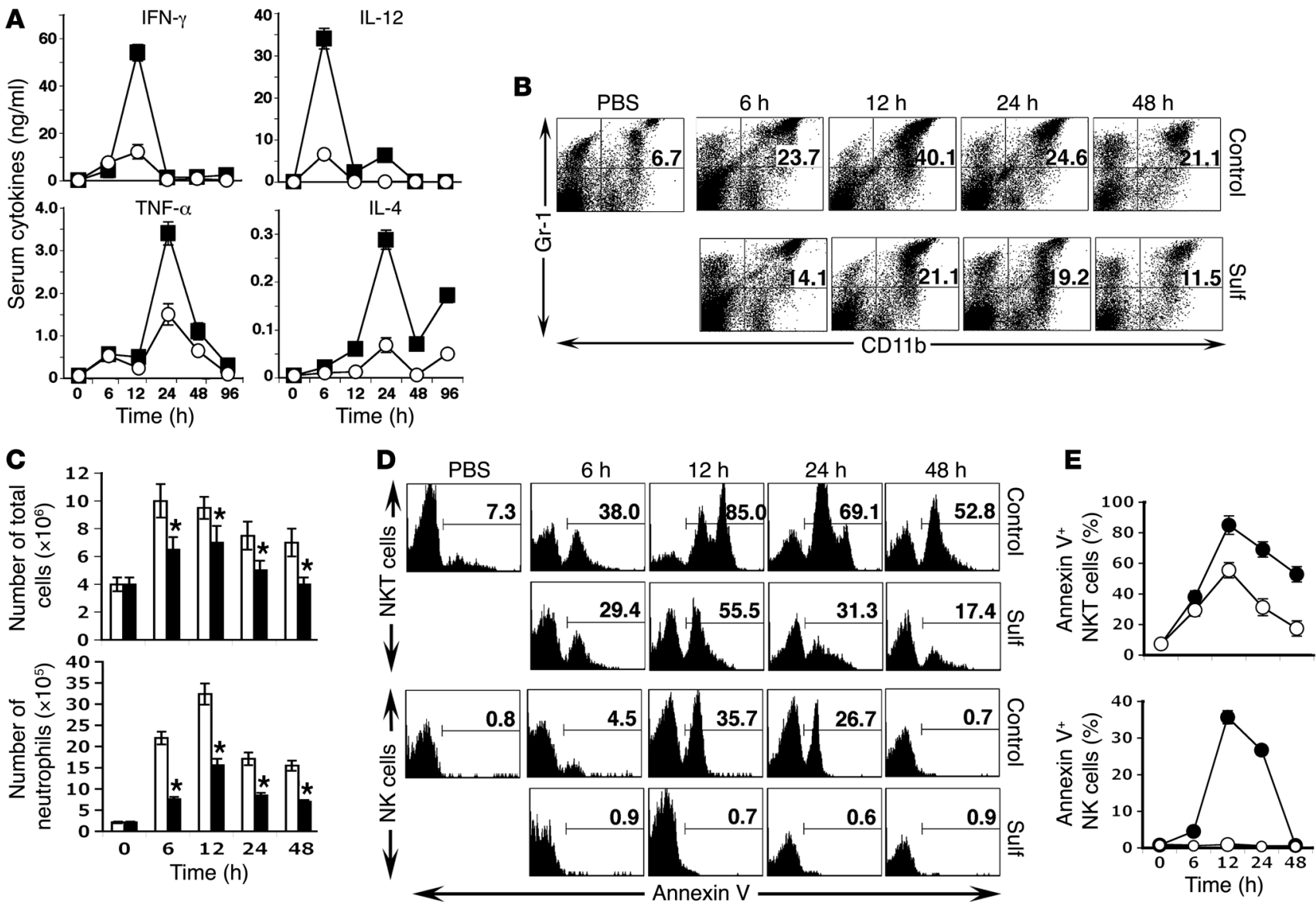

Figure 8

Prevention of ConA-induced hepatitis is associated with inhibition of serum cytokine burst, neutrophil recruitment, and apoptosis of NKT cells. (A) Serum cytokine levels in mice treated with ConA control (filled squares) and sulfatide (open circles) were examined at various time points by ELISA. Values are mean \pm SD of 6 mice per group. $P<0.002$ between groups. (B) FACS profile of Gr- $1+C D 11 b^{+}$cells in the liver of sulfatidetreated or untreated control mice. Numbers within dot plots indicate percent positive cells. (C) Liver leukocytes were isolated at the indicated time points from groups of mice injected with ConA (white bars) or ConA plus sulfatide (black bars), and the total number of live cells was counted. Values are mean \pm SD of 6 mice per group. ${ }^{*} P<0.004$ versus ConA alone. (D) Representative FACS profile showing annexin $V^{+}$NKT and NK cells in the livers of sulfatide-treated and control mice. Numbers above brackets indicate percent positive cells. (E) Summary of annexin $\mathrm{V}^{+} \mathrm{NKT}$ and NK cells as in $\mathbf{D}$ from control (filled circles) or sulfatide-treated (open circles) mice. $P<0.003$ between groups. Data are mean \pm SD of 3 mice per group and are representative of $2-3$ individual experiments.

also been shown to be important in iNKT cell recruitment into the spleen during tolerance induction (39). Inactivation of iNKT cells in recipients of DCs from sulfatide-treated mice clearly indicate that hepatic DCs play a key role in cellular interactions, leading to the unresponsiveness of iNKT cells. Thus DCs activated or modified following interaction with type II NKT cells could be used for intervention in liver inflammation. We have also found that type II NKT-modified DCs were inefficient in priming proteolipid protein-reactive $\mathrm{CD}^{+} \mathrm{T}$ cells that mediate EAE in SJL/J mice (I. Maricic and R. Halder, unpublished observations). Thus the pDC-NKT-mediated pathway may be exploited in the modulation of autoimmune diseases and in antitumor immunity (E. Ambrosino, unpublished observations).

Sulfatide-reactive type II NKT cells are less abundant in mice than are iNKT cells (23). It is interesting that the activation of sulfatidereactive type II NKT cells resulted in an increase in serum IL-12 and IFN- $\gamma$, but not IL-4, as occurred following activation of iNKT by $\alpha$-GalCer. Similar to the role of DC-derived IL- 12 in the antiviral
$(40,41)$ and antimalarial responses mediated by iNKT cells (42), our data suggest a crucial role for hepatic PDC-derived IL-12 in the recruitment and inactivation of iNKT cells. Sulfatide administration prevented ConA-induced hepatitis (Figure 7, A-C) as well as antigen-induced EAE (ref. 23 and our unpublished observations) in WT mice but not in IL-12p40-/- mice. Furthermore hepatic DCs from sulfatide-treated IL-12p $40^{+/+}$but not from IL-12p40-/- mice induce anergy in recipient's iNKT cells (Figure 6). Collectively these data suggest that the DC-generated cytokine/chemokine milieu can mediate differentiation, migration, and recruitment of iNKT cells to modulate autoimmune and infectious diseases.

Several previous studies have shown that intrahepatic iNKT cells are crucial in mediating inflammatory liver disease (6-8). It is clear from our data that anergic iNKT cells are inefficient in recruiting and activating neutrophils into liver parenchyma and thus do not mediate inflammatory liver damage. Serum cytokines, liver enzymes, and NK and NKT cell apoptosis were substantially inhibited following sulfatide-mediated anergy in iNKT cells. Recently, pDCs have 
been shown to act as tolerance-inducing APCs following interaction with $\mathrm{CD} 4^{+} \mathrm{CD} 25^{+}$Tregs and to suppress allo-responses in both mice and in humans $(43,44)$. Thus interaction of $\mathrm{pDC}$ with $\mathrm{CD} 4^{+} \mathrm{CD} 25^{+}$ Tregs or NKT cells can lead to their regulatory phenotype and may represent a novel pathway that can be used to inhibit recruitment of leukocytes into specific tissues in inflammatory conditions.

In general, iNKT cells are autoreactive or memory-like and express early activation markers (45). Accordingly, iNKT cells can be activated even in the absence of exogenous administration of a lipid ligand in the presence of fully activated DCs that can provide either a second signal, the cytokine IL-12 (46), or self glycolipids whose synthesis increases following a bacterial infection (47). Our results indicate that in vivo activation of sulfatide-reactive type II NKT cells does not lead to activation of $\mathrm{mDCs}$, thus suggesting a requirement of fully activated mDCs for the activation of iNKT cells in vivo.

Recently, iNKT cells have been shown to be associated with the increased severity of chronic allergic asthma (48). Alteration in the number or cytokine secretion profile of iNKT cells has also been suggested to play an important role in human type I diabetes (49). Similarly, several studies in experimental models of autoimmunity have shown that the manipulation of iNKT cells, through either elimination or alteration of their cytokine secretion profile, can have significant consequences in disease progression (reviewed in ref. 50). The results presented here demonstrate what we believe to be a novel pathway of interactions among NKT cell subsets mediated by a physiologically relevant self-lipid antigen that can be used to inhibit type I responses and ultimately disease outcome. In addition to the ConA-induced hepatitis, sulfatide-mediated treatment of 3 different EAE models of multiple sclerosis (I. Maricic, unpublished observations) as well as diabetes in NOD mice (our unpublished observations) further elucidate the importance of anergy induction in iNKT cells in the potential treatment of autoimmune diseases. Because CD1 molecules, unlike the class Ia MHC molecules, are nonpolymorphic, insight into these pathways will be extremely valuable in the development of non-HLA-dependent therapeutics for inflammatory diseases.

\section{Methods}

Animals. Female C57BL/6 and C57BL/6-IL-12p40-/- mice (6-8 weeks old) were purchased from The Jackson Laboratory. C57BL/6-CD $1 \mathrm{~d}^{-/-}$and C57BL/6-J $18^{-/-}$mice were originally generated by Van Kaer and Taniguchi $(12,51)$, respectively, and were kindly provided by M. Kronenberg (La Jolla Institute for Allergy and Immunology, La Jolla, California, USA). All mice were bred and maintained in specific pathogen free-conditions. All experiments were approved by the Institutional Animal Care and Use Committee of the Torrey Pines Institute for Molecular Studies.

Reagents. Myelin-derived lipids were purified (>90\% pure) and purchased from Matreya Inc. Synthetic $\alpha$-GalCer was provided by Y. Koezuka (Kirin Brewery Co., Tokyo, Japan). All lipids were dissolved in vehicle ( $0.5 \%$ polysorbate- 20 and $0.9 \% \mathrm{NaCl}$ solution) and diluted in PBS. Sulfatide $(20 \mu \mathrm{g})$ in PBS ( $200 \mu \mathrm{l} /$ mouse), $2 \mu \mathrm{g} \alpha$-GalCer (200 $\mu \mathrm{l} /$ mouse), $2 \mu \mathrm{g} \beta$-GalCer $(200$ $\mu \mathrm{l} /$ mouse), or $200 \mu \mathrm{l}$ PBS were injected i.p. For antibody blocking experiments, mice received blocking IL-12 (p40/p70) [0.3 mg anti-human IL-12 (p40/p70) mAb clone C8.6; eBiosciences], MIP-2 mAbs (0.1 mg anti-mouse MIP-2 mAb clone 40605.11; R\&D Systems), or IgG1 isotype-matched control antibody in PBS (200 $\mu$ l) i.p. 12-24 hours before sulfatide injection. ConA was purchased from Vector Laboratories.

Cell isolation and adoptive transfer. Hepatic lymphocytes were isolated using the Percoll gradient as described previously (23). Briefly, following anesthesia with isoflurane (Baxter), mice were perfused with chilled PBS. Liver was removed, cut into small pieces, and pressed through a $70-\mu \mathrm{m}$ nylon cell strainer (BD Falcon; BD Biosciences) and suspended in DMEM with $2 \%$ heat-inactivated FBS. Cells were washed with medium at $860 \mathrm{~g}$ for $10 \mathrm{~min}$ utes. Liver mononuclear cells (MNCs) were isolated on a Percoll (35\% Percoll containing $100 \mathrm{U} / \mathrm{ml}$ heparin) gradient. Splenocytes were obtained by pressing the spleen through a $70-\mu \mathrm{m}$ nylon strainer and were resuspended in medium followed by lysis of erythrocytes using rbc lysing buffer (SigmaAldrich). CD $11 c^{+}$DCs were purified from liver MNCs by positive selection with CD11 $\mathrm{c}^{+}$Micro Beads on a Mini MACS column (Miltenyi Biotec Inc.) according to the manufacturer's protocol ( $>90 \%$ pure). CD11 $\mathrm{c}^{+} \mathrm{DCs}$ from IL-12p $40^{+/+}$or IL-12p $40^{-/-}$donors were isolated 24 hours after sulfatide injection, and were injected $\left(4-5 \times 10^{5}\right.$ cells/mouse $)$ i.v. into IL-12p $40^{+/+}$ recipients. Two days later, liver MNCs and splenocytes were isolated from recipients and subjected to proliferation assays.

Flow cytometry. MNCs were suspended in fluorescence-activated cell sorting buffer $\left(1-2 \times 10^{6} \mathrm{cells} / \mathrm{ml}\right)$ containing PBS in $0.02 \% \mathrm{NaN}_{3}(\mathrm{w} / \mathrm{v})$ and $2 \%$ FBS $(v / v)$. Cells were first incubated with antibodies against FcR- $\gamma$ (clone 2.4G2; BD Biosciences) and then labeled with the antibodies indicated in Figures 1-6 and 8. All FITC-, PE-, CyChrome-, and allophycocyanin-conjugated $\mathrm{mAbs}$ were acquired from BD Biosciences. PE-labeled $\alpha$-GalCer/ mouse CD1d and sulfatide/mouse CD1d tetrameric complexes were generated with mouse CD1d protein purified using in a baculovirus expression system as described previously (23). Anti-mouse PDCA-1 (clone JF051C2.4.1) was purchased from Miltenyi Biotec Inc. For intracellular cytokine staining (ICCS), liver MNCs were cultured for 4-6 hours with $500 \mathrm{ng} / \mathrm{ml}$ ionomycin and $10 \mathrm{ng} / \mathrm{ml}$ PMA in the presence of Golgi-plug $(1 \mu \mathrm{l} / \mathrm{ml})$. Cells were harvested and washed, and intracellular staining was performed according to the manufacturer's protocol (BD Biosciences). For IL-12 analysis, purified $\mathrm{CD} 11 \mathrm{c}^{+} \mathrm{DCs}$ were incubated with $5 \mu \mathrm{g} / \mathrm{ml}$ LPS or medium alone overnight before ICCS. Analysis was performed using a FACSCalibur instrument with CellQuest software (version 4.0.2; BD).

Hepatitis and histopathology. To induce autoimmune hepatitis, mice were injected i.v. with $10 \mathrm{mg} / \mathrm{kg}$ of ConA. Sulfatide $(20 \mu \mathrm{g})$ was administered i.p. immediately after ConA injection. Control mice were injected with PBS (200 $\mu \mathrm{l} /$ mouse). For histopathology, liver tissue slices were fixed in $10 \%$ formaldehyde solution and kept at room temperature until use. H\&E staining was performed by Pacific Pathology Inc.

ELISPOT, ELISA, and enzyme analysis. The frequency of IFN- $\gamma-$ and IL-4producing cells was determined by cellular ELISPOT assay as described previously $(23,52)$. For ELISA, serum was collected following glycolipid and/or ConA administration and stored at $-20^{\circ} \mathrm{C}$ until use. IFN- $\gamma$, IL-4, TNF- $\alpha$, and IL-12 (p40/p70) levels were measured at $0,1,3,6,12,24$, 48 , and 96 hours using sandwich ELISA as described previously $(23,52)$. Serum levels of ALT and AST were measured by the Laboratory Corporation of America and IDEXX.

Real-time PCR analysis. mRNA was isolated from frozen liver tissue using the RNeasy Mini Kit (QIAGEN) according to the manufacturer's protocol. The specific primers were used as follows: MIP-2 sense, 5'-GAACAAAGG CAAGGCTAACTGA-3'; antisense, 5'-AACATAACAACATCTGGGCAAT-3'; cyclophilin sense, 5'-GGCCGATGACGAGCCC-3'; antisense, 5'-TGTCTTTGGAACTTTGTCTGCAA-3'. Real-time PCR was carried out using Brilliant SYBER Green QPCR kit (Stratagene) on a Stratagene Mx3000p machine. The calculation of comparative mRNA expression was performed by the Stratagene Mx3000p software (version 1.2) and was designated as relative quantity after normalization against internal control gene (cyclophilin) and after consideration of amplification efficiency of individual genes.

Measurement of proliferation responses and CFSE dilution analysis. For proliferation assays, $8 \times 10^{5}$ splenocytes were cultured in vitro for 72 hours in the presence of graded concentrations of $\alpha$-GalCer $(0.1-100 \mathrm{ng} / \mathrm{ml})$, and $\left[{ }^{3} \mathrm{H}\right]$-thymidine incorporation was measured as described previously (23, 
52). For CFSE (Invitrogen) dilution analysis, splenocytes were labeled with $5 \mu \mathrm{M}$ CFSE for 10 minutes at $37^{\circ} \mathrm{C}$ in PBS containing $0.1 \% \mathrm{BSA}$ and washed twice with complete RPMI medium. Labeled splenocytes $\left(3 \times 10^{5}\right.$ cells/well) were then stimulated with $\alpha$-GalCer $(0.1-100 \mathrm{ng} / \mathrm{ml})$ in the absence or presence of cytokines IL-2 or IL-12 (5-10 ng/ml; PEPROTECH) or cells alone for 96 hours in complete RPMI. At the end of the culture, cells were harvested, stained with CyChrome-conjugated anti-TCR- $\beta$ and PE-conjugated $\alpha$-GalCer/CD1d, and analyzed by flow cytometry. After excluding dead cells using forward and side scatter, CFSE dilution was examined gated on $\alpha$-GalCer/CD1d tetramer ${ }^{+}$iNKT cells.

Statistics. Data were analyzed using unpaired, 2-tailed Student's $t$ test by Prism software (version 4; GraphPad Software). A $P$ value less than 0.05 was considered significant.

1. Crispe, I.N. 2003. Hepatic T cells and liver tolerance. Nat. Rev. Immunol. 3:51-62.

2. Calne, R.Y., et al. 1969. Toleragenic effects of porcine liver allografts. Br. J. Surg. 56:692-693.

3. Lueth, S., and Lohse, A.W. 2006. Autoimmune hepatitis. Clin. Med. 6:25-28.

4. Herkel, J., Schuchmann, M., Tiegs, G., and Lohse, A.W. 2005. Immune-mediated liver injury. J. Hepatol. 42:920-923.

5. Tiegs, G., Hentschel, J., and Wendel, A. 1992. A T celldependent experimental liver injury in mice inducible by concanavalin A. J. Clin. Invest. 90:196-203.

6. Diao, H., et al. 2004. Osteopontin as a mediator of NKT cell function in T cell-mediated liver diseases. Immunity. 21:539-550.

7. Kaneko, Y., et al. 2000. Augmentation of Valpha14 NKT cell-mediated cytotoxicity by interleukin 4 in an autocrine mechanism resulting in the development of concanavalin A-induced hepatitis. J. Exp. Med. 191:105-114.

8. Takeda, K., et al. 2000. Critical contribution of liver natural killer T cells to a murine model of hepatitis. Proc. Natl. Acad. Sci. U. S. A. 97:5498-5503.

9. Bendelac, A., Bonneville, M., and Kearney, J.F. 2001. Autoreactivity by design: innate B and T lymphocytes. Nat. Rev. Immunol. 1:177-186.

10. Kronenberg, M., and Gapin, L. 2002. The unconventional lifestyle of NKT cells. Nat. Rev. Immunol. 2:557-568.

11. Brigl, M., and Brenner, M.B. 2004. CD1: antigen presentation and T cell function. Annu. Rev. Immunol. 22:817-890.

12. Kawano, T., et al. 1997. CD1d-restricted and TCRmediated activation of valpha14 NKT cells by glycosylceramides. Science. 278:1626-1629.

13. Kinjo, Y., et al. 2005. Recognition of bacterial glycosphingolipids by natural killer T cells. Nature. 434:520-525.

14. Mattner, J., et al. 2005. Exogenous and endogenous glycolipid antigens activate NKT cells during microbial infections. Nature. 434:525-529.

15. Zhou, D., et al. 2004. Lysosomal glycosphingolipid recognition by NKT cells. Science. 306:1786-1789.

16. Crowe, N.Y., et al. 2003. Glycolipid antigen drives rapid expansion and sustained cytokine production by NK T cells. J. Immunol. 171:4020-4027.

17. Osman, Y., et al. 2000. Activation of hepatic NKT cells and subsequent liver injury following administration of alpha-galactosylceramide. Eur. J. Immunol. 30:1919-1928.

18. Parekh, V.V., et al. 2005. Glycolipid antigen induces long-term natural killer $\mathrm{T}$ cell anergy in mice. J. Clin. Invest. 115:2572-2583. doi:10.1172/JCI24762.

19. Wilson, M.T., et al. 2003. The response of natural killer $\mathrm{T}$ cells to glycolipid antigens is characterized by surface receptor down-modulation and expansion. Proc. Natl. Acad. Sci. U. S. A. 100:10913-10918.

20. Behar, S.M., Podrebarac, T.A., Roy, C.J., Wang, C.R.,

\section{Acknowledgments}

This work was supported by NIH grant R01-CA100660 to V. Kumar. The authors thank Randle Ware and Trevor Smith for critical reading of the manuscript and other laboratory members for their help.

Received for publication January 24, 2007, and accepted in revised form May 8, 2007.

Address correspondence to: Vipin Kumar, Laboratory of Autoimmunity, Torrey Pines Institute for Molecular Studies, 3550 General Atomics Court, San Diego, California 92121, USA. Phone: (858) 455-3870; Fax: (858) 455-3804; E-mail: vkumar@tpims.org. and Brenner, M.B. 1999. Diverse TCRs recognize murine CD1. J. Immunol. 162:161-167.

21. Cardell, S., et al. 1995. CD1-restricted CD4+ T cells in major histocompatibility complex class II-deficient mice. J. Exp. Med. 182:993-1004.

22. Chiu, Y.H., et al. 1999. Distinct subsets of CD1drestricted $T$ cells recognize self-antigens loaded in different cellular compartments. J. Exp. Med. 189:103-110.

23. Jahng, A., et al. 2004. Prevention of autoimmunity by targeting a distinct, noninvariant CD1d-reactive T cell population reactive to sulfatide. J. Exp. Med. 199:947-957.

24. Kronenberg, M., and Rudensky, A. 2005. Regulation of immunity by self-reactive T cells. Nature. 435:598-604.

25. Baron, J.L., et al. 2002. Activation of a nonclassical NKT cell subset in a transgenic mouse model of hepatitis B virus infection. Immunity. 16:583-594.

26. Terabe, M., et al. 2005. A nonclassical non-Valpha14Jalpha18 CD1d-restricted (type II) NKT cell is sufficient for down-regulation of tumor immunosurveillance. J. Exp. Med. 202:1627-1633.

27. Duthie, M.S., Kahn, M., White, M., Kapur, R.P., and Kahn, S.J. 2005. Critical proinflammatory and anti-inflammatory functions of different subsets of CD1d-restricted natural killer T cells during Trypanosoma cruzi infection. Infect. Immun. 73:181-192.

28. Zajonc, D.M., et al. 2005. Structural basis for CD1d presentation of a sulfatide derived from myelin and its implications for autoimmunity. J. Exp. Med. 202:1517-1526.

29. Fuss, I.J., et al. 2004. Nonclassical CD1d-restricted NK T cells that produce IL-13 characterize an atypical Th2 response in ulcerative colitis. J. Clin. Invest. 113:1490-1497. doi:10.1172/JCI200419836.

30. Shamshiev, A., et al. 2000. The alphabeta T cell response to self-glycolipids shows a novel mechanism of CD1b loading and a requirement for complex oligosaccharides. Immunity. 13:255-264.

31. Sidobre, S., et al. 2002. The V alpha 14 NKT cell TCR exhibits high-affinity binding to a glycolipid/ CD1d complex. J. Immunol. 169:1340-1348.

32. Jomantaite, I., et al. 2004. Hepatic dendritic cell subsets in the mouse. Eur. J. Immunol. 34:355-365.

33. Bonder, C.S., Ajuebor, M.N., Zbytnuik, L.D., Kubes, P., and Swain, M.G. 2004. Essential role for neutrophil recruitment to the liver in concanavalin Ainduced hepatitis. J. Immunol. 172:45-53.

34. Campos, R.A., et al. 2003. Cutaneous immunization rapidly activates liver invariant Valpha14 NKT cells stimulating B-1 B cells to initiate T cell recruitment for elicitation of contact sensitivity. J. Exp. Med. 198:1785-1796.

35. Carnaud, C., et al. 1999. Cutting edge: cross-talk between cells of the innate immune system: NKT cells rapidly activate NK cells. J. Immunol. 163:4647-4650.
36. Kappler, J., et al. 1989. V beta-specific stimulation of human T cells by staphylococcal toxins. Science. 244:811-813.

37. Bezbradica, J.S., et al. 2005. Distinct roles of dendritic cells and B cells in Va14Ja18 natural T cell activation in vivo. J. Immunol. 174:4696-4705.

38. Schmieg, J., Yang, G., Franck, R.W., Van Rooijen, N., and Tsuji, M. 2005. Glycolipid presentation to natural killer T cells differs in an organ-dependent fashion. Proc. Natl. Acad. Sci. U. S. A. 102:1127-1132.

39. Faunce, D.E., Sonoda, K.H., and Stein-Streilein, J. 2001. MIP-2 recruits NKT cells to the spleen during tolerance induction. J. Immunol. 166:313-321.

40. Dalod, M., et al. 2002. Interferon alpha/beta and interleukin 12 responses to viral infections: pathways regulating dendritic cell cytokine expression in vivo. J. Exp. Med. 195:517-528.

41. Trinchieri, G. 2003. Interleukin-12 and the regulation of innate resistance and adaptive immunity. Nat. Rev. Immunol. 3:133-146.

42. Schmieg, J., Yang, G., Franck, R.W., and Tsuji, M. 2003. Superior protection against malaria and melanoma metastases by a C-glycoside analogue of the natural killer T cell ligand alpha-Galactosylceramide. J. Exp. Med. 198:1631-1641.

43. Moseman, E.A., et al. 2004. Human plasmacytoid dendritic cells activated by CPG oligodeoxynucleotides induce the generation of CD4+CD25+ regulatory T cells. J. Immunol. 173:4433-4442.

44. Ochando, J.C., et al. 2006. Alloantigen-presenting plasmacytoid dendritic cells mediate tolerance to vascularized grafts. Nat. Immunol. 7:652-662.

45. Bendelac, A. 1995. CD1: presenting unusual antigens to unusual T lymphocytes. Science. 269:185-186.

46. Brigl, M., Bry, L., Kent, S.C., Gumperz, J.E., and Brenner, M.B. 2003. Mechanism of CD1d-restricted natural killer $\mathrm{T}$ cell activation during microbial infection. Nat. Immunol. 4:1230-1237.

47. De Libero, G., et al. 2005. Bacterial infections promote $\mathrm{T}$ cell recognition of self-glycolipids. Immunity. 22:763-772.

48. Akbari, O., et al. 2006. CD4+ invariant T-cell-receptor+ natural killer $\mathrm{T}$ cells in bronchial asthma. N. Engl.J. Med. 354:1117-1129.

49. Wilson, S.B., et al. 1998. Extreme Th1 bias of invariant Valpha24JalphaQ T cells in type 1 diabetes. Nature. 391:177-181.

50. Godfrey, D.I., and Kronenberg, M. 2004. Going both ways: immune regulation via CD1d-dependent NKT cells. J. Clin. Invest. 114:1379-1388. doi:10.1172/ JCI200423594.

51. Mendiratta, S.K., et al. 1997. CD1d1 mutant mice are deficient in natural $\mathrm{T}$ cells that promptly produce IL-4. Immunity. 6:469-477.

52. Jahng, A.W., et al. 2001. Activation of natural killer $\mathrm{T}$ cells potentiates or prevents experimental autoimmune encephalomyelitis. J. Exp. Med. 194:1789-1799. 